\title{
Clinical and Echocardiographic Study in Chronic Atrial Fibrillation
}

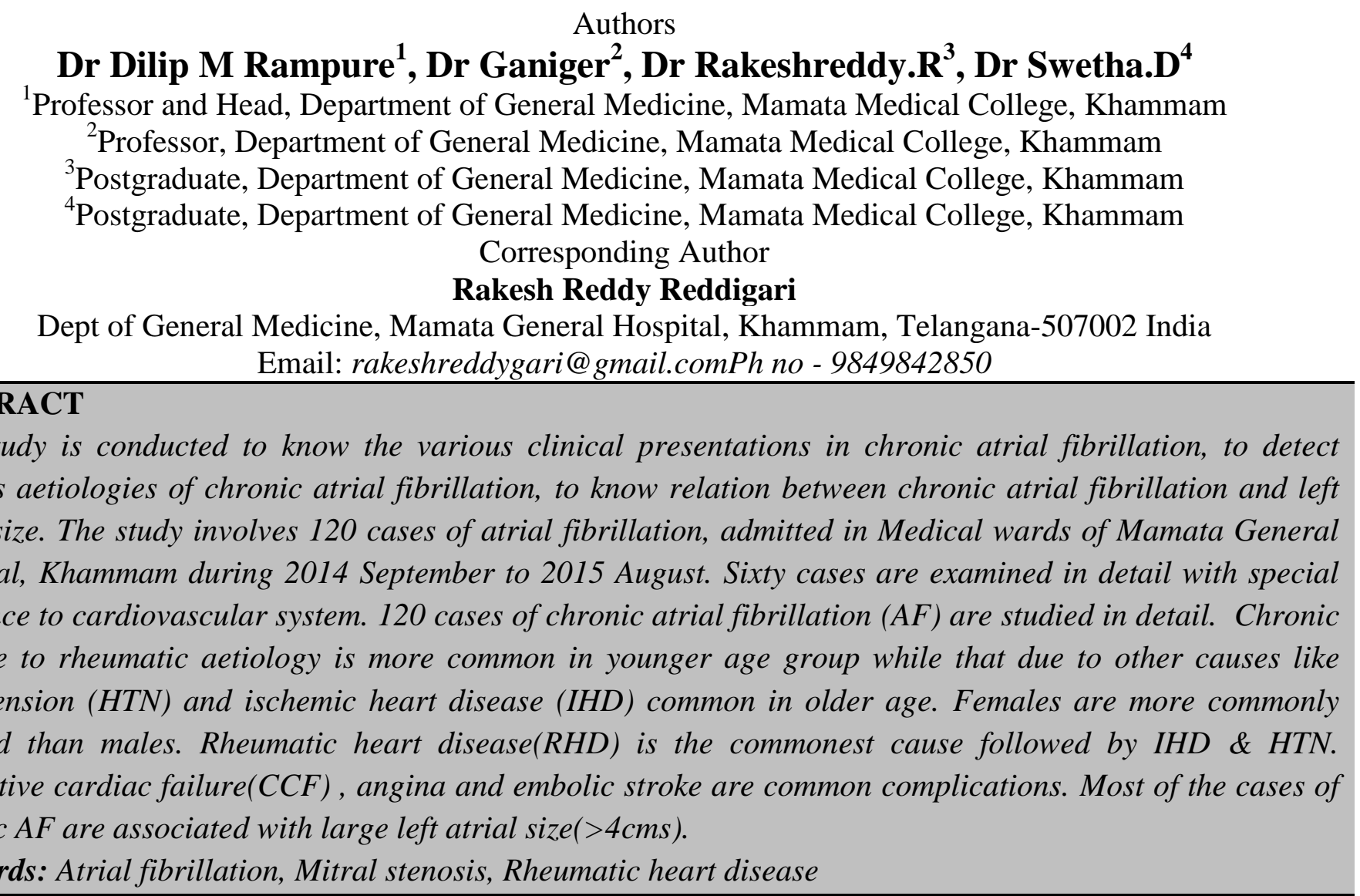

\section{Introduction}

Atrial fibrillation is the most common sustained cardiac rhythm disturbance increasing in prevalence with age. ECG demonstrates rapid fibrillatory waves with changing morphology and ventricular rhythm that is irregularly irregular ${ }^{1 .}$ The overall prevalence of $\mathrm{AF}$ in general population is estimated to be $0.4 \%$ to $1 \%{ }^{2}$. The incidence of $\mathrm{AF}$ is $0.1 \%$ per year in the population below forty years and this increase to $2 \%$ in those over 80 years ${ }^{3}$ The incidence and prevalence of atrial fibrillation increases exponentially with aging $^{4 .}$ The adjusted incidence and prevalence of AF is roughly double for each advancing decade of life $\mathrm{e}^{5,6,7}$. Atrial fibrillation is a supraventricular tachyarrhythmia characterized by uncoordinated atrial activation with consequent deterioration of atrial mechanical function. On the electrocardiogram (ECG) AF is characterized by the replacement of consistent $p$ waves by rapid fibrillatory waves that vary in amplitude, shape and timing, associated with an irregular rapid 
ventricular response when atrioventricular conduction is intact ${ }^{1}$.

\section{Materials and Methods}

The study involves 120 cases of atrial fibrillation, admitted in Medical wards of Mamata General Hospital, Khammam. All cases are examined in detail with special reference to cardiovascular system. Other systems were also examined in detail, whenever it was found necessary. In each case, history of present and past illness was carefully inquired into so as to obtain a complete historical background of case. Investigations like urine examination, complete Blood counts, Erythrocyte sedimentation rate, Blood urea, Serum creatinine, random Blood sugar, serum electrolytes, chest X-ray, electrocardiogram and echocardiography have been carried out. Blood for culture and sensitivity, CT Scan of Brain and Thyroid function tests were done whenever necessary. Echocardiography was done to know about the valvular lesions, mitral valve area (MVA) and enlargement of chambers particularly the left atrium size. Atrial fibrillation is diagnosed using 12 lead Electrocardiogram. On the surface ECG,P waves are absent and are replaced by rapid fibrillatory waves " $\mathrm{f}$ " that vary in size, shape and timing leading to irregular ventricular response. This study includes only chronic $\mathrm{AF}$ (persistent and permanent $)^{8,9}$. New Onset / Acute AFis excluded from the study.

Results A Clinical study of 120 cases of chronic AF

Table 1 showing Age and sex distribution

\begin{tabular}{|l|c|c|c|c|}
\hline $\begin{array}{l}\text { Age } \\
\text { Group }\end{array}$ & Male & Female & Total & Percentage \\
\hline $0-10$ & - & - & - & - \\
\hline $11-20$ & 4 & 2 & 6 & $5 \%$ \\
\hline $21-30$ & 6 & 8 & 14 & $11.67 \%$ \\
\hline $31-40$ & 2 & 20 & 22 & $18.33 \%$ \\
\hline $41-50$ & 18 & 18 & 36 & $30 \%$ \\
\hline $51-60$ & 16 & 8 & 24 & $20 \%$ \\
\hline $61-70$ & 4 & 4 & 8 & $6.67 \%$ \\
\hline $71-80$ & 4 & 4 & 8 & $6.67 \%$ \\
\hline$>80$ & - & 2 & 2 & $1.67 \%$ \\
\hline
\end{tabular}

Out of 120 cases studied 66 were females and 54 were males, showing female predominance. Age range is from 15 years to 90 years.

Table 2 showing Clinical presentation in 120 cases of chronic AF

\begin{tabular}{|l|c|c|}
\hline Complaint & No. of patients & Percentage \\
\hline 1. Dyspnoea & 100 & 83.33 \\
\hline 2. Palpitations & 62 & 51.67 \\
\hline 3. Pedal edema & 32 & 26.67 \\
\hline 4. Chest pain & 36 & 3 \\
\hline 5. Haemoptysis & 2 & 1.67 \\
\hline 6. Paralysis & 16 & 13.33 \\
\hline
\end{tabular}

In this study the main complaints are dyspnoea, palpitations, pedal edema, chest pain, haemoptysis and weakness of limbs. The duration of symptoms ranged from 15 days to 20 years. Shorter duration was noticed in cases of Ischemic Heart Disease (IHD) and longer duration in Rheumatic Heart disease (RHD). Aetiological incidence: In this study aetiology has been established by history, clinical examination, ECG, CXR and Echocardiography. 


\section{JMSCR Vol||3||Issue||10||Page 7736-7741||October}

Table 3 showing aetiological incidence in 120 cases of AF according to sex distribution

\begin{tabular}{|l|c|c|c|c|}
\hline S1 No & Disease & $\begin{array}{c}\text { Total } \\
\text { (Percentage) }\end{array}$ & Male & Female \\
\hline 1 & RHD & $88(73.3)$ & 32 & 56 \\
\hline 2 & IHD & $14(11.67)$ & 10 & 4 \\
\hline 3 & HTN & $6(5)$ & 4 & 2 \\
\hline 4 & DCM & $6(5)$ & 4 & 2 \\
\hline 5 & CHD & $4(3.33)$ & 2 & 2 \\
\hline 6 & COPD & $2(1.67)$ & 2 & - \\
\hline
\end{tabular}

In this study RHD (73.33\%) is the most common cause followed by IHD (11.67\%) and Hypertension (HTN) $(5 \%)$. Female predominance is seen in RHD and male predominance is seen in IHD.

Table 4 showing age, sex incidence according to aetiology: Female group

\begin{tabular}{|l|c|c|c|c|c|c|}
\hline Age Group & RHD & IHD & HTN & DCM & CHD & COPD \\
\hline $11-20$ & - & - & - & - & 2 & - \\
\hline $21-30$ & 8 & - & - & - & - & - \\
\hline $31-40$ & 22 & - & - & - & - & - \\
\hline $41-50$ & 16 & - & - & - & - & - \\
\hline $51-60$ & 6 & - & - & 2 & - & - \\
\hline $61-70$ & 4 & - & - & - & - & - \\
\hline $71-80$ & - & 4 & - & - & - & - \\
\hline$>80$ & & & 2 & & & \\
\hline
\end{tabular}

Table 5-Male Group

\begin{tabular}{|l|c|c|c|c|c|c|}
\hline Age Group & RHD & IHD & HTN & DCM & CHD & COPD \\
\hline $11-20$ & 4 & - & - & - & - & - \\
\hline $21-30$ & 8 & - & - & - & - & - \\
\hline $31-40$ & 2 & - & - & - & - & - \\
\hline $41-50$ & 10 & 2 & - & 2 & 2 & 2 \\
\hline $51-60$ & 8 & 6 & - & 2 & - & - \\
\hline $61-70$ & - & 2 & - & - & - & - \\
\hline $71-80$ & - & - & 4 & - & - & - \\
\hline$>80$ & - & & & & & \\
\hline
\end{tabular}

The above table shows that AF commonly presented in 21-50 years age group. Rheumatic aetiology is most commonly seen below 50 years and IHD \& Hypertensive heart disease commonly seen above 50 years,

Table 6 showing (different) valvular affection in RHDwith AF (88cases)

\begin{tabular}{|l|c|c|}
\hline Value & No. of Patients & Percentage \\
\hline 1. MS & 30 & 34.09 \\
\hline 2. MR & 8 & 9.09 \\
\hline 3. MS + MR & 28 & 31.81 \\
\hline $4 . \mathrm{MS}+\mathrm{MR}+\mathrm{AR}$ & 6 & 6.81 \\
\hline 5. MS + AR & 8 & 9.09 \\
\hline 6. MR + AR & - & - \\
\hline 7. MS + MR + AS & 2 & 2.27 \\
\hline 8. MR + AS + AR & - & - \\
\hline 9. MS + MR + AR + AS & 6 & 6.81 \\
\hline
\end{tabular}

Table 6 shows Mitral Stenosis(MS) is the commonest lesion. Out of 88 cases, 80 cases have MS.Only MS cases are 30 (34.09\%), only Mitral Regurgitation(MR) are 8 (9.09\%) cases. Other common valvular lesions are MS + MR $28(31.81 \%)$. 
Table7 showing Mitral Valve Area(MVA) in RHD associated with Mitral Stenosis (MS).(80 cases)

\begin{tabular}{|l|c|c|}
\hline MVA & No. of patients & Percentage \\
\hline Upto 1 Sq. cms & 52 & 65 \\
\hline $1.1-2$ Sq. cms & 24 & 30 \\
\hline$>2$ Sq. cms & 4 & 5 \\
\hline
\end{tabular}

In this study, MVA ranges from 0.6 to 2.1 Sq. cms.Most of the cases have MVA $<1$ Sq. cms (Severe).Isolated MS have less MVA when compared to othervalvular lesions.

Table 8 shows Left Atrium (L.A). size 120 cases

\begin{tabular}{|l|c|c|}
\hline L.A. size & No. of patients & Percentage \\
\hline$<4 \mathrm{cms}$ & 12 & 10 \\
\hline $4-5 \mathrm{cms}$ & 74 & 61.67 \\
\hline$>5 \mathrm{cms}$ & 34 & 28.33 \\
\hline
\end{tabular}

In this study LA Size ranges from $3 \mathrm{cms}$ to $6.8 \mathrm{cms}$.Most of the cases have LA size between $4-5 \mathrm{cms}$ (61.67\%).Large LA is commonly associated with Regurgitantvalvular lesions (MR-6.8cn).

Table 9 showing LA size in different Valvular lesions with chronic AF:

\begin{tabular}{|l|c|c|c|}
\hline Valvular lesion & \multicolumn{3}{|c|}{ No. of patients with L.A. size } \\
\hline & $<4 \mathrm{~cm}$ & $4-5 \mathrm{~cm}$ & $>5 \mathrm{~cm}$ \\
\hline 1.MS & 6 & 16 & 8 \\
\hline 2. MR & - & 4 & 4 \\
\hline 3. MS + MR & - & 20 & 8 \\
\hline $4 . \mathrm{MS}+\mathrm{MR}+\mathrm{AR}$ & - & 2 & 4 \\
\hline 5.MS + AR & - & 4 & 4 \\
\hline 6. MR + MR & - & - & - \\
\hline 7. MS + MR + AS & - & - & - \\
\hline 8. MS + AS + AR & - & - & - \\
\hline 9. MS + MR + AR + AS & - & 2 & 2 \\
\hline
\end{tabular}

Most of the valvular lesions have LA size between 4 to $5 \mathrm{cms}$. Large LA size of $6.8 \mathrm{cms}$ is seen in Mitral Regurgitation.

Table 10 showing LA sizes in Chronic AF according to aetiology

\begin{tabular}{|l|c|c|c|}
\hline Aetiology & \multicolumn{3}{|c|}{ L.A. Size } \\
\hline 1. Valvular lesions & $<4 \mathrm{~cm}$ & $4-5 \mathrm{~cm}$ & $>5 \mathrm{~cm}$ \\
\hline 2. IHD & 6 & 50 & 32 \\
\hline 3. HTN & 4 & 10 & - \\
\hline 4. DCM & - & 6 & - \\
\hline 5. COPD & - & 4 & 2 \\
\hline 6. CHD & - & 2 & - \\
\hline
\end{tabular}

Valvular lesions are associated with large LA size. Most of the cases with chronic atrial fibrillation are associated with LA size greater than $4 \mathrm{cms}$.

Clots in cardiac chambers L.A. / L.V. In this study, out of 120 cases 6 cases have clots. Out of 6 cases, 4 cases are of Rheumatic aetiology and the clots are present in Left atrium. One presented with embolic stroke. The other 2 cases are Ebstein's Anomaly and the clot was present in Right atrium. 
Table 11 showing complications in 60 cases of AF

\begin{tabular}{|l|c|c|}
\hline Complications & No. of Patients & Percentage \\
\hline 1. CCF & 48 & 40 \\
\hline 2. Angina & 16 & 13.33 \\
\hline 3. Embolic stroke & 16 & 13.33 \\
\hline 4. Haemoptysis & 2 & 1.6 \\
\hline 5. Infective endocarditis & 2 & 1.6 \\
\hline
\end{tabular}

$\mathrm{CCF}$ is the most common (40\%) complication encountered. The incidence of stroke is also high $(13.33 \%)$.Infective Endocarditis is seen in 2 cases.

\section{Discussion}

Age and sex distribution: In present study atrial fibrillation is seen more in the age group below 50 years $(21-50$ years).According to Paul Wood and Lip Gy, Golding DJ ${ }^{10}$ majority of people had AF after the age of 50 years. These differences are because of differences in aetiology. In the present study RHD is more common but in their study HTN and IHD were common. In present study the sex ratio of female to male is $1.22: 1$. According to Lok NS, Lau $\mathrm{CP}^{11}$, the ratio is $1.8: 1$. In both studies female predominance is there. Few other studies showed male predominace ${ }^{12,13,14}$.

Clinical presentation: In present study Dyspnoea $(83.3 \%)$ and palpitations $(51.65 \%)$ are most common presentations. Stroke is seen in $13.33 \%$ of cases. The symptoms are of longer duration in rheumatic aetiology and shorter duration in other causes. In Lok NS, Lau $\mathrm{CP}^{11}$ study dyspnoea (38.1\%) and palpitations (42.3\%) were the most common presentations. Rheumatic heart disease is the commonest cause of chronic AF in our country where as in west Ischemic heart disease and Hypertension is the commonest cause.

Valvular affection in RHD with AF :In the present study of AF, RHD is seen in $34.09 \%$ of patients with isolated MS, $9.09 \%$ of patients with isolated MR. Combined lesions are seen in $31.81 \%$ with MS+MR , $6.81 \%$ with MS+MR+AR and $9.01 \%$ with MS+AR. In Diker et $\mathrm{al}^{15}$ study, $29 \%$ of patients with isolated MS and $16 \%$ of isolated MR were seen. In our study combination of these lesions are common.

MVA in RHD associated with MS: In present study MVA ranges from 0.6 to 2.1sq.cms. Most of the cases of AF are associated with MVA less than 1sq.cms (severe). Isolated MS have less MVA when compared to other valvular lesions.

Left atrial size:In this study left atrial size ranges from $3 \mathrm{~cm}$ to $6.8 \mathrm{~cm}$. In most of the cases LA size is between 4 to $5 \mathrm{~cm}(56.67 \%)$.

Clots in cardiac chambers: In this study out of 120 cases, 6 cases $(5 \%)$ have clots .Out of 6 cases, 4 cases are of rheumatic aetiology and the clots are present in left atrium. 2 cases presented with embolic stroke. The other cases are ebsteinsanomaly and the clot is present in right atrium.

Complications: In this study CCF (40\%) is most common complication followed by angina $(13.33 \%) \&$ stroke (13.33\%). Other major complications are haemoptysis $(1.67 \%)$ and infective endocarditis (1.67\%).In stroke patient's 14 out of 16 cases are of rheumatic aetiology. The other cases dilated cardiomyopathy. In Lip GyGodlging $\mathrm{DJ}^{8}$ study the common complications are $\mathrm{CCF}(30.6 \%) \&$ stroke $18 \%$.

\section{Conclusion}

120 cases of chronic AF studied in detail

1. Chronic AF due to rheumatic aetiology is more common in younger age group while that due to other causes like HTN \& IHD common in older age.

2. Females are more commonly affected than males.

3. RHD is the commonest cause followed by IHD \& HTN.

4. CCF, angina and embolic stroke are common complications.

5. Most of the cases of chronic AF are associated with large left atrial size (>4cms). 


\section{REFERENCES}

1. Eric N Prystowsky, Benzy J Padanilam, Albert L Waldo;.Hurst's: The Heart, edited by Valentinfuster et al. Mcgraw Hill 13thedition 2011. VolI .963-981.

2. Go AS, Hylek EM, Phillips KA et al, Prevalence of atrial fibrillation in adults. JAMA 2001;285:2370-5.

3. Wolf PA, Abbott RD, Kannel WB, Atrial fibrillation: A major contributor to stroke in the elderly. The Framingham study. Arch Internal Medicine 1987; 147:1561-4.

4. Rodney H Falk, MD. Atrial Fibrillation; NEJM .2001;344:1067-1077.

5. Benjamin EJ, Levy D, Vaziri SM, D'Agostino RB, Belanger AJ, Wolf PA. Independent risk factors for atrial fibrillation in a population-based cohort: the Framingham Heart Study. JAMA. 1994; 271: 840-844.

6. Go AS, Hylek EM, Phillips KA, Chang Y, Henault LE, Selby JV, Singer DE. Prevalence of diagnosed atrial fibrillation in adults: national implications for rhythm management and stroke prevention: the Anticoagulation and Risk Factors in Atrial Fibrillation (ATRIA) Study. JAMA.2001; 285: 2370-2375.

7. Psaty BM, Manolio TA, Kuller LH, Kronmal RA, Cushman M, Fried LP, White R, Furberg CD, Rautaharju PM. Incidence of and risk factors for atrialfibrillation in older adults. Circulation. 1997; 96: 2455-2461.

8. Fuster, V Ryden LE . Asinger RW et al. ACC/ AHA /ESC guidelines for the management of patient with atrial fibrillation (committee to develop guidelines for the management of patients with AF )circulation 2001; 104: 2118-2150

9. Levy S. Classification system of AF. Cur opincardiol 2000;15:54-57

10. Lip GyGodlging DJ- A survey of Atrial fibrillation in general practice. British journal of general practice 47(418)n2859,1997.

11. Lok NS, Lau CP- presentation and management of patients admitted with atrial fibrillation. Intrnational journal of cardiology-48(3): 271-8,1995 Mar.3.

12. Furberg CD, Psaty BM, ManolioTA et al. Prevalence of atrial fibrillation in elderly subject (the cardiovascular health study) Ame. J Cardiol 1994; 74 : 236-41.

13. Kannel WB, MC Namara, AbottRD , coronary heart disease and atrial fibrillation, The Framingham study. Am heart J. 1993;106: 389-96.

14. Alfa study- The college of French cardiologists:1999;99:3028-35.

15. Diker E aydogdu S-prevalence and prediction of atrial fibrillation in rheumatic valvular heart disease. American $\mathrm{Jr}$ of cardiology 77(1):96-8, 1996 Jan 